\title{
Assessment of energy expenditure in individuals with post-poliomyelitis syndrome
}

\author{
Avaliação do gasto energético nos indivíduos com síndrome pós-poliomielite \\ Roberto Dias Batista Pereira', Tatiana Mesquita e Silva', Abrahão Augusto Juviniano Quadros', \\ Marco Orsini ${ }^{2,3}$, Beny Schmidt', Helga Cristina Almeida Silva ${ }^{4}$, Acary Souza Bulle Oliveira ${ }^{1}$
}

\begin{abstract}
The objective of this study was to identify energy expenditure, retrospectively, in individuals with post-poliomyelitis syndrome (PPS) in the Brazilian population. Methods: The Baecke questionnaire for the evaluation of habitual physical activity (HPA), assessment of quality of life (WHOQOL-Bref), and the Fatigue Severity Scale were administered to patients with PPS, poliomyelitis sequelae (PS) and to a control group (CG). Participated in the study 116 individuals (PPS=52,PS= 28,CG=36). Results: Patients with PPS tended to increase their HPA from 10 to 20 years of age, compared with those in the PS group and the CG. In the period from 21 to 30 years of age, there was significant increase in the PPS group's occupational physical activity compared to the PS group, and the occupational physical activity (21-30 years of age) correlated with the onset of symptoms of PPS. Conclusion: Patients with PPS had a higher energy expenditure during life, especially in occupational physical activity at ages 21-30 years, suggesting this decade is critical for the development of PPS.
\end{abstract}

Keywords: postpoliomyelitis syndrome; poliomyelitis; energy metabolism.

RESUMO

O objetivo deste estudo foi identificar o gasto energético, retrospectivamente, em indivíduos com síndrome pós-poliomielite (SPP) na população brasileira. Métodos: Foi utilizado o questionário Baecke para avaliação da atividade física habitual (AFH) nos pacientes com SPP, sequela de poliomielite (SP) e grupo controle (GC). Participaram do estudo 116 indivíduos (SPP = 52, SP = 28, GC = 36). Resultados: Pacientes com SPP tendem a aumentar a AFH dos 10 aos 20 anos, comparados com os grupos SP e GC. No período dos 21 aos 30 anos, houve aumento significativo da atividade física ocupacional do grupo SPP em relação ao grupo SP e a atividade física ocupacional (21-30 anos) correlacionou-se com o aparecimento dos sintomas da SPP. Conclusão: Pacientes com SPP apresentam maior gasto de energia durante a vida, especialmente na atividade física ocupacional nas idades 21-30 anos, sugerindo que esta década é crítica para o desenvolvimento da SPP.

Palavras-chave: síndrome pós-poliomielite; poliomielite; metabolismo energético.

The post-poliomyelitis syndrome (PPS) is a late effect of poliomyelitis, classified as motor neuronopathy, since the clinical and histological aspects are closely related to dysfunction of the lower motor neurons ${ }^{1}$. The frequency of PPS varies from $22 \%$ to $80 \%$ in different international studies. A Brazilian study showed a frequency of $77,2 \%$ in patients classified as having PPS, of which $62.8 \%$ were women and $37.2 \%$ were men ${ }^{2}$.

The PPS usually occurs $30-50$ years after the acute polio infection. It is characterized by new symptoms or worsening of previous residual symptoms such as: new weakness, muscle fatigue, new atrophy, muscle pain, joint pain and cold intolerance ${ }^{3,4,5,6}$. Currently, it is recognized as a disease entity defined by the World Health Organization, and is represented in the International Code of Disorders (ICD10/G14) 7 .

Different hypotheses have been proposed for the pathophysiology of PPS ${ }^{8,9,10,11}$, but the most accepted is the theory of "overuse" (overload or overtraining), proposed by Charcot ${ }^{12}$ and defended by others ${ }^{13,14,15,16}$.

The most important characteristic of PPS is the development of a new muscle weakness. This new weakness may occur in muscles that already have some degree of muscle weakness or muscles that were previously committed, and subsequently reinnervated. This new weakness inevitably leads to increased energy expenditure for the performance of routine physical activity ${ }^{17}$.

${ }^{1}$ Universidade Federal de São Paulo, Setor de Investigação nas Doenças Neuromusculares, São Paulo SP, Brasil;

${ }^{2}$ Centro Universitário Augusto Motta, Mestrado em Ciências da Reabilitação, Bonsucesso RJ, Brasil;

${ }^{3}$ Universidade Severino Sombra, Mestrado em Ciências Aplicadas a Saúde, Vassouras RJ, Brasil;

«Universidade Federal de São Paulo, Departamento de Anestesiologia, São Paulo SP, Brasil.

Correspondence: Roberto Dias Batista Pereira; Rua Estado de Israel, 899; 04022-002 São Paulo SP, Brasil; E-mail: betofisio@gmail.com

Conflict of interest: There is no conflict of interest to declare.

Received 18 December 2015; Accepted 21 November 2016. 
Some risk factors, such as age, gender, severity of paralysis, pain, intensity of muscular exercise, or physical activity $^{18,19}$ may contribute to the development of PPS. Possible relationships between these factors and energy metabolism are of paramount importance ${ }^{20}$.

Different methods are used for the subjective assessment of habitual physical activity; most of them are represented by questionnaires coming from epidemiological studies ${ }^{21}$. Assessment of physical activity by questionnaire is a method that is influenced mainly by the ability of people to recall ${ }^{22}$.

The Baecke questionnaire for the evaluation of habitual physical activity ${ }^{23}$, is a recall instrument that is easy to apply and understand; it is a qualitative-quantitative scale and addresses aspects such as occupational physical activity, physical exercise in leisure and activities in leisure and locomotion. This instrument has been used in epidemiological study in the Brazilian population ${ }^{24}$.

The objective of this study was to identify energy expenditure, retrospectively, in individuals with PPS in the Brazilian population, and verify whether physical activity may be a predisposing factor for the development of PPS, or worsening of the patient's symptoms.

\section{METHODS}

Three distinct groups of individuals were evaluated: poliomyelitis sequelae (PS), PPS, and a control group (CG). The population of interest comprised patients with a history of paralytic poliomyelitis who underwent ambulatory monitoring in the Neuromuscular Disorders Unit, at the Federal University of Sao Paulo (UNIFESP), in the municipality of Sao Paulo, Brazil, and healthy individuals (caregivers of patients), between the years 2007-2009.

The inclusion criteria were male and female patients with a confirmed diagnosis of paralytic polio and PPS. Patients older than 60 years and the presence of any disease or medical condition that could lead to muscle weakness were excluded. This study was approved by the Ethics Committee of UNIFESP and all patients involved in the study agreed and signed the informed consent form.

To evaluate habitual physical activity, we used the Baecke questionnaire $^{23}$, which had been translated and validated into Portuguese by Florindo and Latorre ${ }^{24}$.

The Baecke encompasses three levels of physical activity characterized by occupational physical activity (questions 1-8), physical exercise and leisure activities (questions 9-12), and physical leisure and locomotion activities (questions 13-16), all of which comprise the assessment of habitual physical activity. The total score (TS) is the sum of the scores of these three levels. Formulae to calculate the Baecke questionnaire were:

$$
\mathrm{OPA}=\frac{\mathrm{vq} \mathrm{l}+(6-\mathrm{vq} 2)+\mathrm{vq} 3+\mathrm{vq} 4+\mathrm{vq} 5+\mathrm{vq} 6+\mathrm{vq} 7+\mathrm{vq} 8}{8}
$$

$$
\begin{aligned}
\mathrm{PEL} & =\frac{\mathrm{vq} 9+\mathrm{vql} \mathrm{O}+\mathrm{vql}+\mathrm{vql} 2}{4} \\
\mathrm{LLA} & =\frac{(6-\mathrm{vql})+\mathrm{vql}+\mathrm{vql} 5+\mathrm{vql} 6}{4}
\end{aligned}
$$

TS $=$ OPA+PEL+LLA

$\mathrm{vq}=$ value of the question

OPA = occupational physical activity

$\mathrm{PEL}=$ physical exercises in leisure

LLA = physical leisure and locomotion activities

TS = total score

The Baecke questionnaire was applied to the three groups (PS, PPS and CG) just once, assessing the history of physical activity throughout life in periods at 10-20 years of age, 21-30 years of age and in the last 12 months, excluding the occupational activities in the period from 10-20 years, resulting in nine final scores of the respective periods (Figure 1).

For the classification of the energy expenditure of occupational physical activity and the types of exercise that were not in the standardization profile ${ }^{23}$, we used the studies by Ainsworth et al. ${ }^{25}$ and McArdle et al. ${ }^{26}$ as reference. The first study was a coding scheme for the classification of energy cost of human physical activities, and the latter proposed levels of classifications of human energy expenditure of physical activity (based on a multiple of the resting metabolic rate).

For fatigue evaluation, we use the Fatigue Severity Scale ${ }^{27}$. It consists of nine items. Individuals record their responses from 1-7 (1 means that they disagree completely and 7 indicates that they fully agree with the statement). This scale assesses the complaint of fatigue in the previous two weeks.

We also used the abbreviated World Health Organization Quality of Life assessment tool $^{28}$. This questionnaire has 26 questions, the first two are general and the other 24 divided into four domains: physical (dom 1), psychological (dom 2), social relationships (dom 3), environment (dom 4) and overall. Steps for checking and cleaning data and computing facet and domain scores were:

Recode q3 q4 q26 (1=5) (2=4) (3=3) (4=2) (5=1).

\begin{tabular}{|c|c|c|}
\hline $10-20$ & $21-30$ & after 30 \\
\hline years & years & years \\
\hline \multirow[t]{2}{*}{ Questionnaire } & Questionnaire & Questionnaires \\
\hline & & last 12 months \\
\hline \multirow[t]{2}{*}{ BQHPA } & BQHPA & BQHPA \\
\hline & OPA & OPA \\
\hline PEL & PEL & PEL \\
\hline LLA & LLA & LLA \\
\hline \multirow[t]{5}{*}{ TS } & TS & TS \\
\hline & & last 2 weeks \\
\hline & & SSF \\
\hline & & last 2 weeks \\
\hline & & WHOQOL-Bref \\
\hline
\end{tabular}

compute dom $1=($ mean.6 $(\mathrm{q} 3, \mathrm{q} 4, \mathrm{q} 10, \mathrm{q} 15, \mathrm{q} 16, \mathrm{q} 17, \mathrm{q} 18)) * 4$.

compute dom $2=(\operatorname{mean} .5(\mathrm{q} 5, \mathrm{q} 6, \mathrm{q} 7, \mathrm{q} 11, \mathrm{q} 19, \mathrm{q} 26)) * 4$

Figure 1. Methodology to apply the questionnaires. 
compute dom $3=($ mean. $2(\mathrm{q} 20, \mathrm{q} 21, \mathrm{q} 22)) * 4$

compute dom 4 = (mean.6 (q8, q9, q12, q13, q14, q23, $\mathrm{q} 24, \mathrm{q} 25)) * 4$

compute overall $=($ mean. $2(\mathrm{q} 1, \mathrm{q} 2)) * 4$

Analyses were performed by PRISM 3 software, by comparing their percentage by category, calculation of mean, median and standard deviation.

Continuous variables with normal distribution were tested by the Kolmogorov-Smirnov test.

Analysis of variance (ANOVA) was used to compare the groups when presented with parametric data. When statistically significant differences were found, the analysis was complemented by Tukey's test.

Analysis of variance (Kruskall-Wallis) was used to compare the groups when presented with non-parametric data. When statistically significant differences were found, analysis was complemented by Dunn's test.

Evaluation of linear correlation was made using the Spearman's (r) correlation coefficient. For all tests, results were considered statistically significant when $\mathrm{p}<0.05$.

\section{RESULTS}

One hundred and sixteen individuals participated in the study, 52 with PPS, 28 with PS and 36 in the CG. The gender distribution of the CG was 19 women (52.7\%) and 17 men (47.3\%); in the PS group: 17 women (60.7\%) and 11 men (39.3\%); and in the PPS group there were 26 women (50\%) and 26 men (50\%).

The average age for each group was: $42.86 \pm 9.22$ years for the CG; $43.31 \pm 6.91$ years for the PS group; and $43.83 \pm 6.65$ years for the PPS group (ranging from 30 to 59 years). Measures of central tendency and dispersion for anthropometric variables, assessed by group, are presented in Table 1.

The lowest age at which acute poliomyelitis occurred was 23 days and the highest was eight years; the average was 19.71 months (one year and seven months), with a standard deviation of 16.8 months (1.4 years), and the median was 18 months (nine and 24 months). The average age of onset of new symptoms of PPS was $37.7 \pm 6.3$ years (24-53 years).

On the Fatigue Severity Scale, there was a significant difference $(p<0.0001)$ between the CG $(17.56 \pm 11.4)$, the

Table 1. Mean values and standard deviations of the anthropometric characteristics of the groups involved in the study.

\begin{tabular}{lccc} 
Variable & CG $(n=36)$ & PS $(n=28)$ & PPS $(n=52)$ \\
\hline Height $(\mathrm{cm})$ & $170.5 \pm 10.9 *$ & $161.2 \pm 8.0$ & $163.4 \pm 10.3$ \\
Weight $(\mathrm{Kg})$ & $74.6 \pm 17.6$ & $62.7 \pm 15.8 * *$ & $68.7 \pm 15.4$ \\
BMI $\left(\mathrm{Kg} / \mathrm{m}^{2}\right)$ & $25.5 \pm 4.1$ & $23.8 \pm 4.9$ & $25.5 \pm 4.1$ \\
\hline
\end{tabular}

Test ANOVA (one way analysis of variance); ${ }^{*} \mathrm{p}=0,0007$ vs PS and PPS; $\star * p=0,0124$ vs CG

CG: control group; PS: poliomyelitis sequelae; PPS: post-poliomyelitis syndrome; BMl: body mass index.
PS group (27.29 \pm 20.5$)$ and PPS group (51.48 \pm 14.21$)$. The PPS group showed higher fatigue scores, with $92.3 \%$ of patients being classified with fatigue. In contrast, in the PS and PPS groups, there was no relationship between fatigue and other criteria evaluated in this study (demographic, anthropometric, history of poliomyelitis, quality of life and energy expenditure).

The group of patients with PPS showed an index of quality of life significantly worse in the physical, psychological and environment domains, when compared with the other groups (CG and PS). There was no difference in the social networking domain (Table 2).

The PPS group showed an increase in energy expenditure in their occupational activities (professional), compared to the PS group in the period from 21 to 30 years of age (Figure 2).

Occupational physical activity between 21 and 30 years of age showed correlations with other variables in the survey (Table 3 ).

Table 2. Classification of scores for each group of domains of WHOQOL-Bref.

\begin{tabular}{lcccc}
$\begin{array}{l}\text { Dominion } \\
\text { WHOQOL }\end{array}$ & $\begin{array}{c}\text { CG } \\
(n=36)\end{array}$ & $\begin{array}{c}\text { PS } \\
(n=28)\end{array}$ & $\begin{array}{c}\text { PPS } \\
(n=52)\end{array}$ & -value \\
\hline Physical & $75.9 \pm 14.3$ & $67.9 \pm 17.1$ & $42.4 \pm 16.5$ & $<0.0001^{\mathrm{a}}$ \\
Psychological & $73.6 \pm 13.4$ & $73.5 \pm 15.6$ & $59.3 \pm 16.9$ & $<0.0001^{\mathrm{b}}$ \\
$\begin{array}{l}\text { Social } \\
\text { relationships }\end{array}$ & $74.6 \pm 20.5$ & $72.7 \pm 21.1$ & $67.8 \pm 18.5$ & (ns) 0.128 \\
Environment & $66.1 \pm 17.5$ & $62.7 \pm 17.0$ & $56.7 \pm 15.7$ & $=0.0312^{c}$ \\
\hline
\end{tabular}

Test ANOVA (one way analysis of variance) with Tukey's post-test, significant difference: "group PPS vs PS and CG; broup PPS vs PS and GC; 'group PPS vs CG. CG: control group; PS: poliomyelitis sequelae; PPS: post-poliomyelitis syndrome; WHOQOL: World Health Organization Quality of Life scale.

\section{OCCUPATIONAL PHYSICAL ACTIVITY (OPA)} 21 to 30 years of age

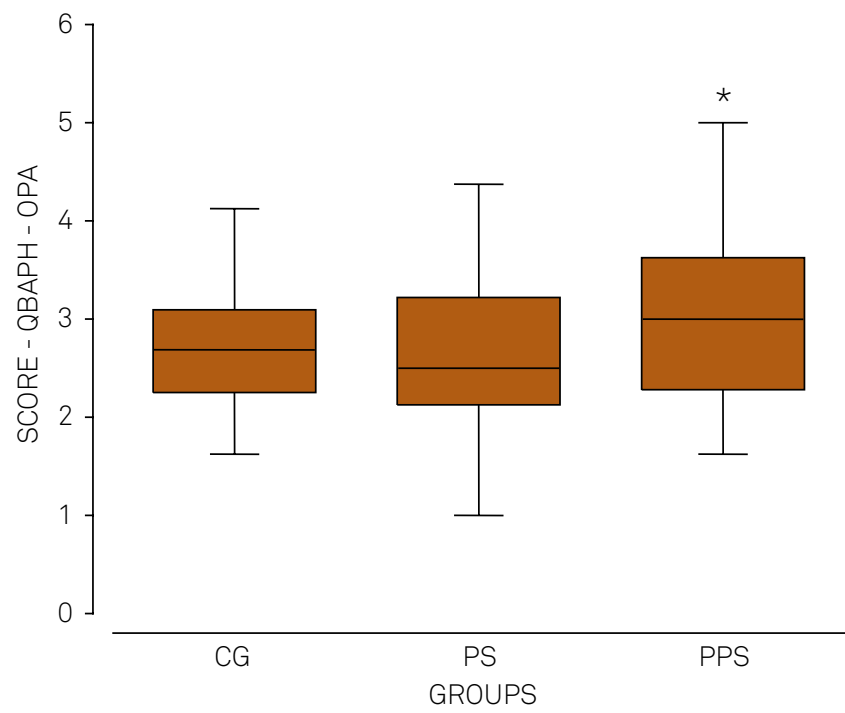

${ }^{*} p<0,05$ vs PS (Test Kruskal-Wallis). CG: control group; PS: poliomyelitis sequelae;PPS: post-poliomyelitis syndrome;OPA: occupational physical activity. Figure 2. Longitudinal comparison of the period from 21 to 30 years of age between CG, PS and PPS of OPA score. 
The Figure 3 shows that the PPS group, during the evaluation of physical activity performed in the previous 12 months, had a lower energy expenditure in all scores of the Baecke Questionnaire of Habitual Physical Activity, in relation to the PS and CG.

\section{DISCUSSION}

The aim of this study was to describe the profile of energy expenditure using the Baecke Questionnaire of Habitual Physical Activity, showing the relationship between habitual physical activity and the development of symptoms of PPS. In this study, it was important to assess whether physical activity may be a predisposing factor for the development of PPS, or worsening of their symptoms.

Fatigue has been found with high frequency affecting, on average, two-thirds of patients with PPS. This finding can be seen both in studies in the United States ${ }^{29}$ and in other

Table 3. Spearman's correlation coefficients and p values between occupational physical activity (21 to 30 years of age) and the variables years of study, acute polio and age of onset of new symptoms.

\begin{tabular}{lcc}
\hline Variables & $\begin{array}{c}\text { Correlation } \\
\text { coefficients }(r)\end{array}$ & $p$-value \\
\hline Education (years of study) & -0.3720 & 0.0066 \\
Acute poliomyelitis & -0.2803 & 0.0390 \\
Age at onset of PPS & -0.2796 & $<0.0447$ \\
\hline
\end{tabular}

Brazilian studies ${ }^{2,30}$. The study by Conde et al. ${ }^{30}$ showed that fatigue in patients with PPS is not related to time of day (morning or evening) but with the type of activity. In our research we analyzed the history of physical activity, professions and sports practiced and did not find any relationship with the variable of fatigue. This could be explained by two hypotheses: fatigue is an independent symptom that deserves specific management; or fatigue is not a good marker of PPS.

Patients with PPS were found to have a poor quality of life compared to the PS and CG groups, mainly in the physical, psychological and environmental domains. The presentation of new symptoms alone, is likely to lead to an impaired quality of life compared to the other groups.

The three groups (CG, PS and PPS) showed a gradual and significant increase in scores of occupational physical activity and total scores over the three periods analyzed. But there was a gradual and significant decrease over the years in physical activity scores in leisure, and physical activity in leisure and locomotion, most likely due to changes in lifestyle, resulting in inactivity in leisure sporting practices.

However, in studied clinical period (previous 12 months), clinical worsening in the patients with PPS may explain why they could not perform activities of leisure, as opposed to lack of opportunity, lack of desire or pleasure linked to another factor. Both the PS and PPS group had a history of sequelae and physical disabilities, but only the PPS group showed a significant decrease in all their habitual physical activities (occupational physical activity, physical exercise and leisure and locomotion activities, and total scores) in the previous 12 months.

LAST 12 MONTHS

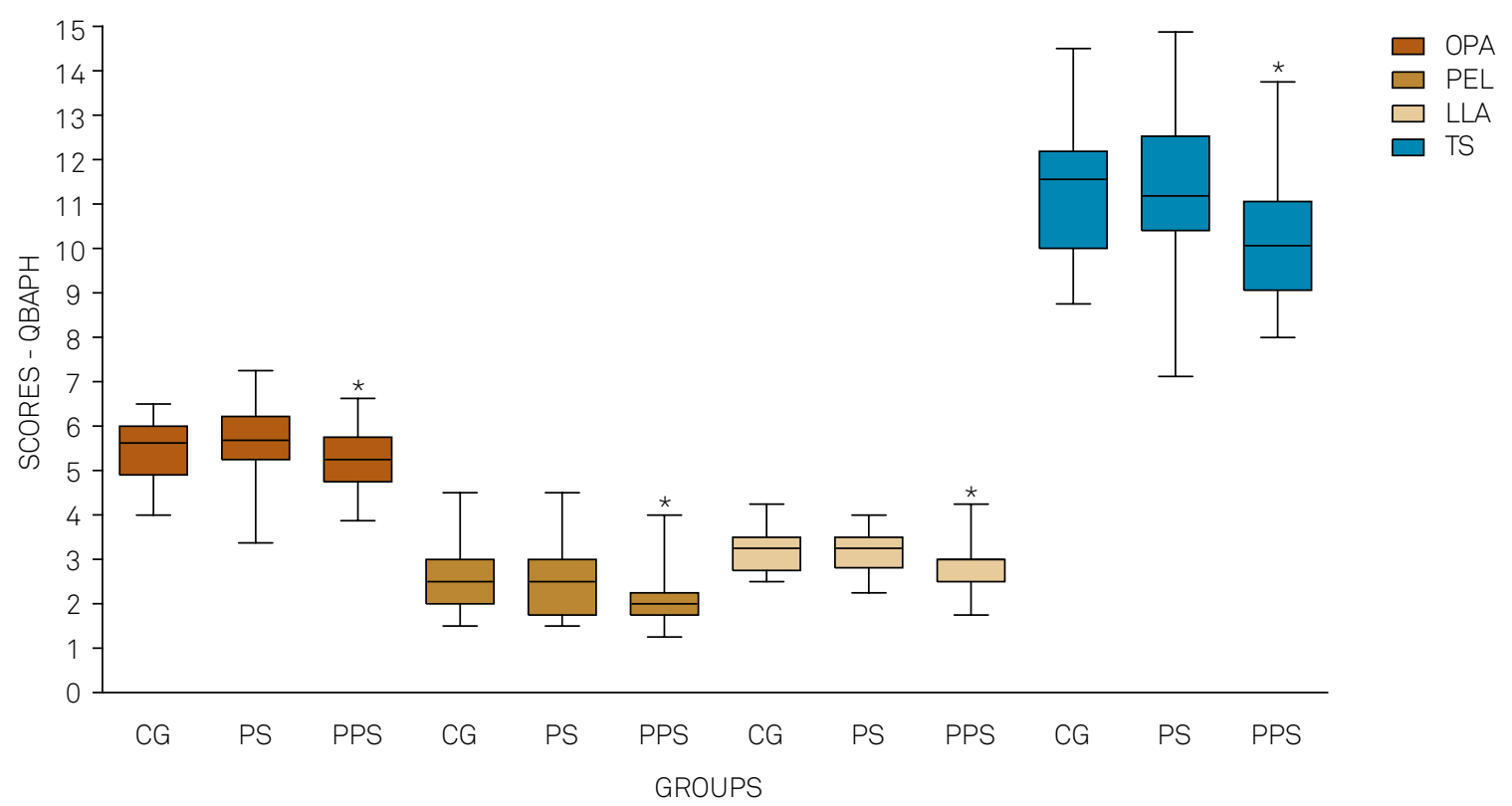

CG: control group; PS: poliomyelitis sequelae; PPS: post-poliomyelitis syndrome; OPA: occupational physical activity; PEL: physical exercises in leisure; LLA: physical leisure and locomotion activities; TS: total score. 
On the other hand, patients with PPS had a higher energy expenditure in occupational physical activity, in the period from 21 to 30 years of age, which was the only factor that corroborates the hypothesis of "overuse".

Considering that PPS is a disease with giant motor units, the increased energy expenditure in any domain of the Baecke questionnaire could indicate an overload in motor units ${ }^{3}$.

The PPS group showed a negative correlation between occupational physical activity, from 21 to 30 years of age, and onset of new symptoms, indicating that the occupational physical activity (profession) exercised in this period is the factor that provided the physical overload causing the earlier appearance of new symptoms ${ }^{13}$.

The PPS group also showed a negative correlation between occupational physical activity, from 21 to 30 years of age, and the educational level, indicating that those who performed more physical activity in their occupation (profession) in this period had a low educational level. This finding indicates that a high level of education may possibly be a protective factor for PPS.

The PPS group showed a negative correlation between occupational physical activity, from 21 to 30 years of age and the age of acute poliomyelitis, indicating that those who had polio later had less energy expenditure in their occupational activities in the period. Therefore, the age of the acute poliovirus infection negatively affected the work performance of patients, corroborating the statement about the severity of sequelae and physical losses of those patients with PPS.
Because this study was performed in a research center that specialized in neuromuscular diseases, the search for the patients was passive and spontaneous. The patients evaluated were those with more symptoms or who had any social and/or legal necessity. However, even though using a questionnaire as a research tool, which allowed the retrospective analysis of energy expenditure, the patients in question had no difficulty in understanding and completing the questionnaire, and this corresponded to a longer period of educational study (over 15 years of study: $\mathrm{PPS}=48 \%$, $\mathrm{PS}=28.6 \%$ and $\mathrm{CG}=33.3$ ).

The study of an energy expenditure profile in individuals with a history of prior paralytic poliomyelitis showed that the PPS is a nosological condition with its own characteristics, and the overuse of motor units during life is one of the causal factors; it is directly linked with the historical expenditure of energy during life; PPS patients had a higher energy expenditure, especially in occupational physical activity, between 21 and 30 years of age, suggesting that this decade is critical for the development of this condition; at the present time, patients with PPS have a different status in relation to the PS and CG groups, with a higher frequency of fatigue, lower scores on usual physical activities and consequently poorer quality of life; being overweight can be an aggravating factor for the development or intensification of these limitations.

Considering that PPS may have a relationship with greater physical activity in a given period of life and/or increased basal metabolism ${ }^{31}$, future research is needed to compare the Fatigue Severity Scale with basal metabolic measures.

\section{References}

1. Abroms JF, Bresnan MJ, Zuckerman JE, Fischer EG, Strand R. Cervical cord injuries secondary to hyperextension of the head in breech presentations. Obstet Gynecol. 1973;41(3):369-78.

2. Stoll BJ, Kliegman RM. Delivery room emergencies. In: Behrman RE, Kliegman RM, Jenson HB, editors. Nelson Text book of pediatrics. 17th ed. Philadelphia, PA: Saunders; 2004. p. 569-72.

3. Emerson NW, et al. Fetus and the neonatal birth injury. In: Behrman RE, Kliegman RM, Jenson HB, editors. Nelson text book of pediatrics. 15th ed. Philadelphia, PA: Saunders; 1996. p. 561-6.

4. Hankins GD, Clark SM, Munn MB. Cesarean section on request at 39 weeks: impact on shoulder dystocia, fetal trauma, neonatal encephalopathy, and intrauterine fetal demise. Semin Perinatol. 2006;30(5):276-87. https://doi.org/10.1053/j.semperi.2006.07.009

5. Henderson SG, Sherman LS. The Roentgen anatomy of the skull in the newborn infant. Radiology. 1946;46(7):107-18. https://doi.org/10.1148/46.2.107

6. Lindgren $L$. The lower parts of the uterus during the first stage of labour in occipito-anterior vertex presentation: studies by means of intrauterine tokography. Acta Obstet Gynecol Scand. 1955;34(Suppl 2):1-79. https://doi.org/10.3109/00016345509154530

7. Moloy HC. Studies on head molding during labor. Amer J Obstet Gynec. 1942;44(5):762-82. https://doi.org/10.1016/S0002-9378(15)30603-7

8. Bhagwanani SG, Price HV, Lawrence KM, Ginz B. Risks and prevention of cervical cord injury in the management of breech presentations with hyperextension of the fetal head. Am J Obst Gynec. 1973;115(8):1159-61. https://doi.org/10.1016/0002-9378(73)90573-5

9. Bucher HU, Boltshauser E, Friderich J, Isler W. Birth injury to the spinal cord. Helv Paediatr Acta. 1979;34(6):517-27.

10. Byers RK. Spinal-cord injuries during birth. Dev Med Child Neurol. 1975;17(1):103-10. https://doi.org/10.1111/j.1469-8749.1975.tb04967.x

11. Cole VA, Durbin GM, Olaffson A, Reynolds EOR, Rivers RPA, Smith JF. Pathogenesis of intraventricular haemorrhage in newborn infants. Arch Dis Child. 1974;49(9):722-8. https://doi.org/10.1136/adc.49.9.722

12. Ford FR. Breech delivery in its possible relation to injury of the spinal cord with special reference to infantile paraplegia. Arch Neurol Psychiat. 1925;14(6):742-50. https://doi.org/10.1001/archneurpsyc.1925.02200180013002

13. Freud S. Die Infantile CerebralHihmung: Specielle Pathologie und Therapie. Wien;1897.

14. Nicholson L. Caput succedaneum and cephalohematoma: the Cs that leaves bumps on the head. Neonatal Netw. 2007;26(5):277-81. https://doi.org/10.1891/0730-0832.26.5.277

15. Harcke HTJr, Naeye RL, Storch A, Blanc WA. Perinatal cerebral intraventricular hemorrhage. J Pediatr. 1972;80(1):37-42. https://doi.org/10.1016/S0022-3476(72)80450-5

16. Harwood-Nash DC, Hendrick EB, Hudson AR. The significance of skull fractures in children: a study of 1,187 patients. Radiology. 1971;101(1):151-5. https://doi.org/10.1148/101.1.151 
17. Korobkin R. The relationship between head circumference and the development of communicating hydrocephalus in infants following intraventricular hemorrhage. Pediatrics. 1975;56(1):74-7.

18. Krishnamoorthy KS, Shannon DC, DeLong GR, Todres ID, Davis KR. Neurologic sequelae in the survivors of neonatal intraventricular hemorrhage. Pediatrics. 1979;64(2):233-7.

19. Little WJ. Course of lectures on the deformities of the human frame. Lancet. 1844;41(1072):809-15. https://doi.org/10.1016/S0140-6736(02)64521-0

20. McDonald MM, Koops BL, Johnson ML. Timing and etiology of intracranial hemorrhage in the newborn. In: Second Special Laboratories Conference on Perinatal Intracranial Hemorrhage. Columbus, Ohio: Ross Laboratories; 1982. p. 221-32.

21. Ment LR, Duncan CC, Scott DT, Ehrenkranz RA. Posthemorrhagic hydrocephalus: low incidence in very low birth weight neonates with intraventricular hemorrhage. J Neurosurg. 1984;60(2):343-7. https://doi.org/10.3171/jns.1984.60.2.0343

22. Neville IS, Amorim RL, Paiva WS, Sanders FH, Teixeira MJ, Andrade AF. Early surgery does not seem to be a pivotal criterion to improve prognosis in patients with frontal depressed skull fractures. Biomed Res Int. 2014;2014:879286. https://doi.org/10.1155/2014/879286

23. Natelson SE, Sayers MP. The fate of children sustaining severe head trauma during birth. Pediatrics. 1973;51(2):169-74.

24. Roberts $\mathrm{MH}$. The spinal fluid in new-born with special reference to intracranial hemorrhage. JAMA. 1925;85(7):500-3. https://doi.org/10.1001/jama.1925.02670070020006

25. Zalatimo O, Ranasinghe M, Dias M, lantosca M. Treatment of depressed skull fractures in neonates using percutaneous microscrew elevation. J Neurosurg Pediatr. 2012;9(6):676-9. https://doi.org/10.3171/2012.2.PEDS11304

26. Weiner EJ, Mclntosh MS, Joseph MM, Maraqa N, Davis PG. Neonatal scalp abscess: is it a benign disease? J Emerg Med. 2011;40(5):e97101. https://doi.org/10.1016/j.jemermed.2009.08.019

27. Collins K, Reed R. Birth trauma. In: Collins KA, Byard RW. Forensic pathology of infancy and childhood. New York: Springer; 2014. p. 139-68.

28. Habibi Z, Meybodi AT, Haji Mirsadeghi SM, Miri SM. Burr-hole drainage for the treatment of acute epidural hematoma in coagulopathic patients: a report of eight cases. J Neurotrauma. 2012;29(11):2103-7. https://doi.org/10.1089/neu.2010.1742

29. Jung SW, Kim DW. Our experience with surgically treated epidural hematomas in children.J Korean Neurosurg Soc. 2012;51(4):215-8. https://doi.org/10.3340/jkns.2012.51.4.215

30. Roberts $\mathrm{MH}$. The spinal fluid in newborn with special reference to intracranial hemorrhage. JAMA. 1925;85:500. https://doi.org/10.1001/jama.1925.02670070020006 DUPLICATA DA 24

31. Health problems of newborns. Hockenberry M, Wilson D. Wong's essentials of pediatric nursing. 9th ed. Saint Louis: Mosby, 2013. p. 274-367.

32. Swanson AE, Veldman A, Wallace EM, Malhotra A. Subgaleal hemorrhage: risk factors and outcomes. Acta Obstet Gynecol Scand. 2011;91(2):260-3. https://doi.org/10.1111/j.1600-0412.2011.01300.x

33. Gupta SN, Kechli AM, Kanamalla US. Intracranial hemorrhage in term newborns: management and outcomes. Pediatr Neurol. 2009;40(1):1-12. https://doi.org/10.1016/j.pediatrneurol.2008.09.019

34. Brittain C, Muthukumar P, Job S, Sanka S. "Ping pong" fracture in a term infant. BMJ Case Rep. 2012;2012:pii: bcr0120125631. https://doi.org/10.1136/bcr.01.2012.5631

35. Kerr HA. Closed head injury. Clin Sports Med. 2013;32(2):273-87. https://doi.org/10.1016/j.csm.2012.12.008

36. Ekéus C, Högberg U, Norman M. Vacuum assisted birth and risk for cerebral complications in term newborn infants: a populationbased cohort study. BMC Pregnancy Childbirth. 2014;14(1):36. https://doi.org/10.1186/1471-2393-14-36

37. Reichard R. Birth injury of the cranium and central nervous system. Brain Pathol. 2008;18(4):565-70. https://doi.org/10.1111/j.1750-3639.2008.00205.x

38. Hehir MP, Reidy FR, Wilkinson MN, Mahony R. Increasing rates of operative vaginal delivery across two decades: accompanying outcomes and instrument preferences. Eur J Obstet Gynecol Reprod Biol. 2013;171(1):40-3. https://doi.org/10.1016/j.ejogrb.2013.08.015

39. Manning JJ, Adour KK, Facial paralysis in children. Pediatrics. 1972;49(1):102-9.

40. Gowers WR. Clinical lecture on birth palsies. Lancet. 1888;131(3372):709-11. https://doi.org/10.1016/S0140-6736(02)15842-9 